\title{
La revelación del misterio de la Trinidad en Xavier Zubiri ${ }^{1}$
}

\author{
Hugo Gudiel, S.J., \\ Centro de Reflexión Teológica, \\ San Salvador
}

\section{Introducción}

Xavier Zubiri divide la exposición y preocupación teórica de "El problema teologal del hombre" en tres grandes apartados ${ }^{2}$. En el primero, aborda el análisis filosófico de la cuestión de Dios. Es lo que se recoge en su obra póstuma El hombre y Dios (1984). A continuación estudia El problema filosófico de la historia de las religiones, obra igualmente póstuma, publicada con ese mismo título (1993). Finalmente, expone el cristianismo como religión de "deiformación". Es en este último apartado donde nuestro autor "trata sistemáticamente los grandes temas de la teología. Por eso podemos referirnos a ellos, aunque sea en primera aproximación, como los "escritos teológicos"”3.

1. A partir de este momento, el editor de la obra El problema teologal del hombre: Cristianismo, donde aparece este artículo sobre la Trinidad, sigue el texto de la tercera parte del curso sobre el problema teologal del hombre, que Zubiri presentó en 1971 ( $c f$ r. ibid., nota 1, p. 87). Esta observación cronológica es fundamental para el estudio de nuestro autor, porque "en el año 1971 Zubiri intenta ya una interpretación global del cristianismo. Esta interpretación global no es una mera suma de respuestas filosóficas a problemas concretos planteados por la teología, sino que incluye y supone una pregunta por las relaciones entre la filosofía de Zubiri, tomada en bloque, y la historia del pensamiento teológico" (A. González, La novedad teológica de la filosofía de Zubiri, Madrid, 1993, p. 5).

2. Sobre el tema, véase la reciente tesis doctoral de J. M. Melero Martínez, El problema teologal del hombre en Xavier Zubiri, Universidad de Murcia, 2008.

3. A. González, La novedad teológica de la filosofía de Zubiri, óp. cit., p. 3. Del mismo autor puede verse también "El problema de la teología en Zubiri", Cultura de Guatemala, 1 (1996), pp. 99-121. 
Tales escritos fueron recogidos, también póstumamente, en la obra titulada El problema teologal del hombre: Cristianismo (1997)4. Este es el contexto en el que hay que ubicar el trabajo de Zubiri sobre la Trinidad (cfr. PTHC 87-147)5.

El objetivo primordial de este trabajo es presentar, en modo descriptivo, la concepción del misterio del Dios uno y trino expuesta en la tercera parte de la obra de Zubiri, dedicada al problema teologal del hombre. ¿Cuáles son los rasgos más significativos que emergen de esa conceptuación personal que Zubiri tiene sobre la Trinidad? ¿Puede dicha conceptuación abrir perspectivas para una interpretación original y novedosa sobre la revelación del misterio de Dios que, al mismo tiempo, abra la posibilidad de una verdadera fundamentación del Dios trino en su revelación? He aquí las preguntas que pueden orientar la lectura de esta exposición.

Este artículo sobre la Trinidad desde la perspectiva zubiriana tiene tres secciones. La primera está dedicada a Cristo, el Espíritu Santo y el misterio de Dios. En la siguiente sección se expone el misterio de Dios en la revelación, partiendo del Nuevo Testamento y terminando con la definición dogmática de Dios. Finalmente, Zubiri conceptúa en modo original, desde su filosofía, lo que entiende por el misterio de Dios. Veamos la primera cuestión.

\section{Cristo, Espíritu Santo y misterio de Dios}

Es sabido que desde el punto de vista de Zubiri, la religión aparece como la mera plasmación de la religación ${ }^{6}$. Y el cristianismo es una religión, es decir, "es una plasmación de la religación en la entrega del hombre" a Dios?. En esa plasmación, la religión cristiana tiene una singularidad, y consiste en que la "plasmación y el plasmante son un momento intrínseco y formal de la propia divinidad, a la cual la religión va a hacer acceder al hombre". En consecuencia, desde el cristianismo, el ser humano no solo accede a Dios, sino que accede a Dios por el mismo Dios (PTHC 87).

4. Una valoración global del problema teologal del hombre, precisamente con motivo de la publicación de este último trabajo dedicado al cristianismo, puede verse en D. Gracia, "El problema teologal del hombre", en www.zubiri.net/foro/ NonCGIForum2/HTML/000001.htm1,2000, pp. 1-15.

5. A partir de este momento utilizaremos en nuestro trabajo, la sigla PTHC para referimos a El problema teologal del hombre: Cristianismo, con su/s respectiva/s página/s de referencia.

6. Sobre la importancia de esta tesis, véase nuestro reciente trabajo "Realidad humana y religación en Zubiri y su recepción en Ellacuría", Revista Latinoamericana de Teología (78), 2009, pp. 299-334.

7. Un estudio sobre la cuestión de la entrega en su dimensión humana, religiosa y cristiana, desde la perspectiva del problema teologal del hombre en Zubiri, en nuestra tesis doctoral H. C. Gudiel García, La fe según Xavier Zubiri, Roma, 2006. 
Ahora bien, ¿"en qué consiste este Cristianismo"? (PTHC 87). Es lo que se clarifica a continuación.

\subsection{La obra de Cristo por historia, doctrina y espiración}

El cristianismo es "obra" de Cristo. Efectivamente, aquel no solo es consecuencia de lo que Cristo hizo, sino que Cristo mismo "hizo" el cristianismo. Pero este también es una obra ejecutada por el propio Cristo. Por tanto, el cristianismo en cuanto obra ejecutada por Cristo es, ante todo, una obra de carácter histórico (PTHC 89).

Pero además, Cristo instruye de "palabra". En este sentido, la obra de Cristo no solo es histórica, sino también doctrinal. Ambas dimensiones están profundamente articuladas. En efecto, "los momentos más pedestres de la historia de Cristo son, en definitiva, enseñanza. Y, recíprocamente, las enseñanzas de Cristo están, en una o en otra forma, ancladas en sucesos reales y efectivos de su vida". Por tanto, tenemos una acción histórica y otra acción de carácter doctrinal unidas. Es la constitución de la religión viva en una comunidad que se congrega en torno a Cristo, pero, sobre todo, que "ha vivido íntima y profundamente de él" (PTHC 90).

Pues bien, "esta vida, esta tradición viva de carácter histórico y doctrinal a un tiempo es lo que constituye precisamente la revelación". Aquí la revelación significa que aquello que Cristo hace, de algún modo manifiesta lo que es Dios $(c f r$. Sal 19,2). He aquí la revelación. Es revelación por lo que Cristo dice y hace, pero también por el lugar en donde lo dice y lo hace (PTHC 90). "Donde lo hizo y como lo hizo: dentro de una tradición israelita, en una vida concreta de Belén, de Nazaret de Galilea, y luego en una vida pública en Cafarnaum, Jerusalén, etc." (PTHC 90-91).

Por tanto, la obra de Cristo es histórica y doctrinal "en el sentido de una tradición viva y además reveladora" (PTHC 91).

Además de histórica y doctrinal, hay que destacar que el sentido de lo que Cristo había hecho, y lo que quedaba por hacer y decir, corre a cargo del Espíritu de la verdad ( $c f r$. Jn 16, 12-15) $)^{9}$. En este sentido, el cristianismo es obra del Espíritu Santo. Este es enviado por Cristo y por el Padre. Es el Espíritu Santo

8. "Los cielos cuentan la gloria de Dios, el firmamento anuncia la obra de sus manos" (Sal 19, 2), NBJ.

9. En Juan 16, 12-15 se lee: "Mucho tengo todavía que deciros, pero ahora no podéis con ello. Cuando venga él, el Espíritu de la verdad, os guiará hasta la verdad completa; pues no hablará por su cuenta, sino que hablará lo que oiga, y os explicará lo que ha de venir. Él me dará gloria, porque recibirá de lo mío y os lo explicará a vosotros. Todo lo que tiene el Padre es mío. Por eso he dicho: Recibirá de lo mío y os lo explicará a vosotros", NBJ. 
"quien desvela el sentido profundo de lo que tiene que ocurrir y, sobre todo, de lo que ha ocurrido" (PTHC 91).

En definitiva, "por historia, por doctrina y por espiración, la obra de Cristo" es el cristianismo (PTHC 91).

\subsection{Universalidad histórica y misterio de Dios}

Con lo anteriormente expuesto, se fijan unos primeros caracteres del cristianismo $^{10}$.

\subsubsection{Universalidad del cristianismo}

La posición de Cristo y el cristianismo frente a la gentilidad se resume, ante todo, en su carácter de "universalidad" (PTHC 91).

En esta universalidad tienen un papel fundamental los Apóstoles y el Espíritu Santo. En efecto, "con san Pablo y apoyado en el Espíritu Santo, el concilio de Jerusalén toma posición frente a la circuncisión y a la presunta necesidad de ser israelita antes de ser cristiano" (PTHC 91-92).

Esto es así porque la decisión de los Apóstoles dice que "ha parecido bien al Espíritu Santo y a nosotros no imponeros más cargas de las indispensables" (Hch 15,28 ). Esta gentilidad incluye "todas las religiones del imperio, sobre todo las religiones de misterios" (PTHC 92).

\subsubsection{Universalidad histórica}

Además, el Espíritu Santo ilumina y asiste constantemente la inteligencia de todos los fieles. En consecuencia, la "humanidad es siempre susceptible de recibir nuevas revelaciones". Naturalmente, Zubiri es consciente de que la revelación "está conclusa", pero al mismo tiempo precisa que esto no significa que ella esté "agotada". Son dos cosas distintas (PTHC 92).

De esta manera, "la obra de Cristo, por lo que él hizo, por la tradición viva en la que sus apóstoles y discípulos continuaron su obra y dieron cuerpo a lo que habían recibido de Cristo, bajo la dirección y la inspiración interna del Espíritu Santo, se constituye precisamente en una religión de universalidad" (PTHC 92-93).

Pero en rigor se trata de una universalidad de carácter histórico. Es decir, es una universalidad histórica dirigida a los seres humanos "concretos que, partiendo justamente de donde estaban, de Palestina o Antioquía, lentamente iban a enseñar al resto de la humanidad lo que es Cristo y lo que es su obra". Y, además, esta revelación es "completa y conclusa" (PTHC 93).

10. Sobre estos caracteres, véase PFHR 260 y ss. (cfr. PTHC 91, nota 1). 


\subsubsection{Dimensiones del misterio de Dios}

La religión cristiana así entendida tiene un capítulo fundamental, que en este contexto es el que interesa averiguar, y que se refiere a la siguiente cuestión: "Qué es ese Dios que el Cristianismo predica y revela". En otras palabras: "Qué es Dios para el Cristianismo" (PTHC 93).

Antes que nada, se observa que todo lo que en última instancia concierne a Dios es "misterio absoluto". Aquí la expresión misterio no se refiere en modo alguno a algo oscuro o impenetrable (PTHC 93) ${ }^{11}$.

Desde una primera dimensión, misterio significa más bien que si los seres humanos lo conocen, es porque justamente corresponde al "arcano de las decisiones de la voluntad divina el haberlo revelado a los hombres y el haber hecho las cosas que la divinidad ha hecho con los hombres"12. Desde esta perspectiva, naturalmente, todo es un misterio. Lo es en el sentido de que "responde en una o en otra forma a un designio" de Dios (PTHC 93) ${ }^{13}$.

Pero en el misterio también puede haber una segunda dimensión. En efecto, "a veces puede ser misterio porque no puede no pertenecer al arcano de la voluntad de Dios" (PTHC 93-94). En este segundo caso, naturalmente, el misterio es "absoluto". Por tanto, es misterio no solo porque lo ha decidido la voluntad divina, sino también por la naturaleza de su propio "objeto" (PTHC 94).

He aquí lo que atañe a la cuestión ¿qué es Dios? Dios es misterio, y es misterio absoluto por razón de su objeto, y porque ese objeto no puede ser absoluta y totalmente descubierto por la inteligencia ( $c f r$. PTHC 94).

Lo anterior no quiere decir que el misterio sea oscuridad total. Más bien significa, para Zubiri, que el misterio "comparte muchas veces esa condición paradójica de un foco que derrama luz alrededor y que, sin embargo, él es muy oscuro, y solamente la luz que derrama alrededor puede revertir y hacer más claro aquello que inicialmente puede presentarse como oscuro en el presunto foco luminoso". Obviamente, lo que sea Dios como misterio es "lo más oscuro que puede darse. Pero ese misterio derrama luz a su alrededor, y hace que, en

11. Esta manera de entender el misterio está muy en la perspectiva de una concepción negativa del misterio, y se encuentra muy difundida, incluso dentro del ámbito de la teología; cfr E. Jüngel, Dios como misterio del mundo, Salamanca, Ediciones Sígueme, 1984, p. 325.

12. Estas cursivas son nuestras.

13. Una concepción positiva y bíblica del "misterio" puede verse en E. Jüngel, Dios como misterio del mundo, óp. cit., pp. 324-339. También en K. Rahner, "Sobre el concepto de misterio en la teología católica", en Escritos de Teología, IV, pp. 53-95. Aludiendo precisamente a este artículo, W. Kasper dice que "K. Rahner es el teólogo que más ha profundizado en la teologia del misterio" (W. Kasper, El Dios de Jesucristo, p. 155). 
una o en otra forma, pueda el hombre revertir con más claridad en punto a ese propio foco luminoso". Esta reversión es precisamente la "conceptuación" del misterio (PTHC 94).

Ciertamente, ni en este mundo ni en el otro, el ser humano puede tener una "comprensión adecuada, exhaustiva y formal de lo que es Dios". Sin embargo, "entre una visión y una comprensión exhaustiva hay una cosa distinta, que es la conceptuación". Esa es la vía intelectiva en virtud de la cual el hombre estima que, "prolongada hasta Dios, conducirá precisamente a lo que es él. Y una vez que a Dios se le vea, esa visión de Dios ratificará en una o en otra forma el camino conceptualmente emprendido hacia él" (PTHC 94) ${ }^{14}$.

Pues bien, ¿cuál es la idea que el cristianismo tiene de ese Dios en su misterio? Es lo que Zubiri trata de responder en las dos siguientes secciones: explicando primero lo que es el misterio de Dios y, luego, conceptuando ese misterio (cfr. PTHC 95).

\section{El misterio de Dios en la revelación}

De entrada, Zubiri plantea en esta sección la siguiente pregunta que, a mi juicio, permite orientar la lectura y comprensión de este tema: "¿En qué consiste el misterio mismo de Dios en la revelación?". Para ello, parte de lo que es Dios en el Nuevo Testamento, luego recoge los conceptos esenciales de la definición dogmática de Dios (PTHC 96).

14. En este contexto vale la pena tomar en consideración la actitud de san Agustín en la búsqueda del misterio del Dios uno y trino, expresada precisamente en su tratado sobre la Trinidad: "Andamos, es cierto, buscando, no una trinidad cualquiera, sino la Trinidad que es Dios; verdadero, sumo y único Dios. Tú, que esto oyes, ten paciencia: aún andamos buscando, y nadie con razón reprende al que se afana en tal empeño, siempre que busque, firme en la fe, algo que es muy difícil de conocer o expresar". Algunas líneas después, san Agustín prosigue afirmando que "la fe cierta es principio de conocimiento; pero nuestra ciencia solo se perfecciona después de esta vida, cuando veamos cara a cara a Dios. Tengamos esto presente, conoceremos que es más seguro el deseo de conocer la verdad que la necia presunción del que toma lo desconocido como cosa sabida. Busquemos como si hubiéramos de encontrar, y encontremos con el afán de buscar. Cuando el hombre cree acabar, entonces principia" (san Agustín, Tratado sobre la santísima Trinidad, Libro IX, capítulo I, en Obras de san Agustin, V, Madrid, 1948). Las dos últimas líneas del texto de san Agustín expresan una actitud intelectual que está muy presente en la búsqueda de la verdad en Zubiri ( $c f r$. SH 676 y el "Prólogo a la tercera edición" de CLF, p. iv). 


\subsection{Dios en el Nuevo Testamento ${ }^{15}$}

\subsubsection{Dios Padre ${ }^{16}$}

Ante todo, recordemos que en la perspectiva de Zubiri, el monoteísmo entra en el mundo con el Dios Elohim, "amigo de la familia de Abraham"17. Y aquel alcanza su plena madurez en la predicación de Cristo $^{18}$. Entonces, ya no se trata simplemente de un Dios amigo de la familia, sino fundamentalmente de un Dios que es el Padre de todos los seres humanos ${ }^{19}$. Recordemos también que la inteligencia humana puede acceder y, de hecho, accede a admitir la realidad de $\operatorname{Dios}^{20}$. Ahora bien, justo aquí es donde cabe plantearse la siguiente pregunta: "¿Qué relación hay entre lo que la inteligencia humana puede adquirir por sí misma y esto de que Dios sea Padre?" (PTHC 96).

Nuestro autor responde a esta cuestión afirmando que el "Padre" puede ser entendido en dos sentidos. Desde un primero, "el Padre se distingue del Hijo y del Espíritu Santo. Es el Padre en cuanto Padre”. Un segundo sentido, en cambio, se refiere al "Padre como principio radical de todo lo real, y además de la propia vida intradivina". Desde esta segunda perspectiva, "materialmente, el Dios que la razón prueba es justamente el Padre. Es decir, la realidad absolutamente absoluta que es el principio de todo lo real, dentro de Dios y fuera de Dios. Es la radicalidad absoluta" (PTHC 97) ${ }^{21}$.

15. Sobre este tema puede verse también K. Rahner, "Theos en el Nuevo Testamento", en Escritos de Teologia, I, pp. 89-156.

16. Desde una perspectiva propiamente teológico-trinitaria, véase la obra de F. X. Durrwell, Dios nuestro Padre, Salamanca, 1990; en concreto, pueden verse las páginas 13-34. También, G. J. Zarazaga, Dios es comunión, Salamanca, 2004, pp. 276-280.

17. Sobre esta primera etapa del monoteísmo en Zubiri, véase nuestra tesis H. C. Gudiel García, La fe según Zubiri, óp. cit., pp. 254-256.

18. Sobre esta sexta etapa del monoteísmo en Zubiri, véase ibid., pp. 263-264.

19. La cuestión de la evolución histórica del monoteísmo la ha tratado ampliamente Zubiri en PFHR, pp. 208-231. Una síntesis de las siete etapas en que Zubiri divide esta evolución del monoteísmo puede verse en H. C. Gudiel García, La fe según Xavier Zubiri, óp. cit., pp. 253-266.

En una sintesis global y magistral de las etapas del monoteísmo, Zubiri dice que con el cristianismo aparece "no solamente un Dios de una familia, de un pueblo, de una monarquía, de un resto de Israel, de una iglesia nacional, sino que aparece una cosa distinta: aparece un Dios de toda la humanidad. Es el universalismo, el monoteísmo universalista" (PFHR 227).

20. Sobre la justificación que Zubiri ha realizado de la cuestión de la realidad de Dios, puede verse nuestro trabajo H. C. Gudiel García, La fe según Xavier Zubiri, óp. cit., pp. $99-112$.

21. Zubiri ha expuesto sus pasos en la justificación racional de esta realidad absolutamente absoluta de Dios en HD 135-164. Sobre ello, véase también nuestro trabajo H. C. Gudiel García, La fe según Xavier Zubiri, óp. cit., pp. 99-112. 


\subsubsection{EI Hijo y Espíritu Santo}

Ahora bien, Dios Padre, según el Nuevo Testamento, tiene además un Hijo y un Espíritu Santo. Pero aquí esta cuestión se comienza a complicar, porque en ningún sitio del Nuevo Testamento se sostiene la existencia de un solo Dios verdadero y de tres personas distintas. Esta negación tiene varios puntos de apoyo ( $c f r$. PTHC 97).

En primer lugar, Zubiri afirma que en ningún pasaje del Nuevo Testamento, exceptuando naturalmente el del final del Evangelio de Mateo, se enuncian las tres personas divinas de una manera copulativa ( $c f r$. PTHC 97) $)^{22}$.

Según Mateo, Jesús habló a los discípulos y les dijo: "Toda potestad, todo poder me ha sido dado en el cielo y en la tierra" (Mt 28, 18). Y en el mismo Evangelio se añade a continuación: "Marchando, instruid a todas las gentes, bautizándolas en el nombre del Padre y del Hijo y del Espíritu Santo" (Mt 28, 19). Obviamente, "esta frase es copulativa y no puede tener mayor claridad". Sin embargo, es improbable que la pronunciara Cristo en esos términos. La razón de ello radica en que, "como es bien sabido, basta recurrir a los Hechos para saber que los apóstoles no bautizaron en nombre de la Trinidad, sino en nombre de Jesucristo" (PTHC 97) ${ }^{23}$.

Naturalmente, "bautizar en nombre de Cristo no quiere decir que no se bautice en nombre de la Trinidad, sino que no se pronuncia la fórmula trinitaria". En todo caso, Mateo 28, 18-19 "es un pasaje en el que la exégesis bíblica está de acuerdo en reconocer que se trata de un desarrollo, todo lo inspirado y legítimo que se quiera, pero un desarrollo" (PTHC 98).

En segundo lugar, también suele decirse que el Padre, el Hijo y el Espíritu Santo son tres "personas". Pero Zubiri constata inmediatamente que el término "persona" jamás aparece en el Nuevo Testamento; aparece más tarde con

22. En opinión de W. Trilling, estos tres versículos que se encuentran al final del Evangelio de Mateo (Mt 28, 18-20) figuran entre las declaraciones más importantes de todo el libro. El autor afirma que el Evangelio de Mateo hay que entenderlo "desde atrás". Solo bajo este supuesto teológico de Mateo 28, 16-20 se ha escrito todo el Evangelio. Más aún: el final del mismo se vuelve en cierto modo el principio y enseña a entender todo el Evangelio "desde atrás". Por tanto, Mateo 28, $18-20$ es la clave para el entendimiento de todo el libro. Véase W. Trilling, El verdadero Israel, 29-30.

23. En la nota a Mateo 28, 19 de la Nueva Biblia de Jerusalén, se lee: "Es sabido que los Hechos hablan de bautizar 'en el nombre de Jesús', ver Hch 1, 5+; 2, 38 . Más tarde se habrá hecho explícita la vinculación del bautizado con las tres personas de la Trinidad". 
Tertuliano ${ }^{24}$. La palabra "persona", en efecto, "no tuvo un carácter formalmente revelador y revelado en los primeros siglos del Cristianismo" (PTHC 98).

Se trata de un dato importante que ha de ser tomado en consideración, porque cuando en la actualidad se afirma que el "Padre, el Hijo y el Espíritu Santo son tres personas, uno piensa que la persona es un ente dotado de libertad, de iniciativa, de responsabilidad propia" (PTHC 98-99). Pero afirmar esto sería para Zubiri caer en una perfecta herejía, en un "triteísmo"25. Por tal razón, él prefiere hablar de tres "términos". La persona, pues, significa aquí pura y simplemente un término (PTHC 99).

Finalmente, en tercer lugar, puede afirmarse que en el Nuevo Testamento jamás se dice de estos tres términos que sean uno. Ciertamente, en el cuarto Evangelio hay algunos pasajes en donde aparecen los dos términos. Es lo que sucede en el caso concreto de Juan 17, 21-22, en donde tenemos una unidad. Sin embargo, cabe aclarar que ahí se trata de una unidad de "concordia". En efecto, "es la unidad de una vida, de una operación, pero no la unidad que se quiere expresar cuando se dice que hay tres personas distintas y uno solo Dios verdadero" [sic] (PTHC 99).

En la primera carta de san Juan, también hay un pasaje en el que se expresa "que los tres son testigos, el Espíritu, el Agua y la Sangre, y los tres convergen en una cosa" (1 Jn 5, 7-8). Pero ahí no se afirma que sean uno (PTHC 99). En consecuencia, no puede decirse en modo explícito y formal "que hay una unidad física entre el Padre, el Hijo y el Espíritu Santo". Esto no quiere decir, obviamente, que "esta unidad esté excluida, sino que está percibida de una manera más o menos indiscernida" (PTHC 100).

En definitiva, en el texto revelado se afirma que tenemos un mismo Dios, y que este tiene tres términos: Padre, Hijo y Espíritu Santo. Y esos tres términos no constituyen una triplicidad, sino una "Trinidad" 26 . He aquí el contenido del texto propiamente revelado. De aquí surge precisamente la cuestión: "cómo ha entendido la Iglesia esta revelación". Es lo que se responde a continuación (PTHC 100).

24. Sobre ello, véase L. F. Ladaria, El Dios vivo y verdadero, pp. 152-153; en la p. 152 de la misma obra, véase la interesante nota 39.

25. "En opinión de algunos teólogos contemporáneos (Barth, Rahner), seguir usando la fórmula tradicional de "tres personas" origina involuntariamente un triteísmo irreflejo a causa de la prof unda modificación del concepto de persona, identificado hoy en día con autoconciencia" (S. del Cura Elena, "Triteísmo", en DTDC, p. 1398).

26. La palabra Trinidad "apareció por primera vez en Teófilo de Antioquía a finales del siglo II". En el año 675 el Concilio de Toledo definió precisamente que Dios no es triplicidad, sino Trinidad (DH 528) (PTHC 100). Sobre el término "Trinidad", véase también L. F. Ladaria, El Dios vivo y verdadero, óp. cit., pp. 142-144. 


\subsection{Definición dogmática de Dios}

La revelación de la Trinidad no puede ser reducida a ser el enunciado de un teorema, sino que es un movimiento progresivo, que va revelando la Trinidad en distintos aspectos y estratos. En consecuencia, "dentro de su esfera legítima, es menester que todos estos estratos y todos estos pasos sean formalmente mantenidos dentro de la visión del dogma trinitario" (PTHC 101).

Según la opinión personal del filósofo, "esos tres estadios responden a tres conceptos, cada uno de los cuales se funda en el siguiente, y cada uno de los siguientes tiene por misión no solamente decir lo que dice, sino además hacer posible el anterior" (PTHC 101). Esos conceptos progresivos son la funcionalidad, la transcendencia y la consustancialidad.

\subsubsection{La funcionalidad de la Trinidad y sus caracteres}

La finalidad de la revelación no es la de ser una comunicación meramente cognoscitiva de Dios, sino que consiste fundamentalmente en posibilitar y fundamentar la vida religiosa de los seres humanos (cfr. PTHC 101).

Desde esta perspectiva, la revelación de Dios tal como es en sí mismo incluye también al mundo en su totalidad. De tal manera que todo el mundo "manifiesta, denuncia y revela lo que es justamente ese Dios que fundamenta la realidad del mundo y la vida religiosa en él". El mundo revela a Dios precisamente al instalar la vida religiosa y referirla a Dios. La revelación tiene por finalidad expresarnos "algo de Dios en sí mismo, pero para fundamentar la vida religiosa". Y el mundo en su totalidad es una "revelación y una denunciación de ese fundamento". Pues bien, tomados unitariamente ambos caracteres son lo que Zubiri llama la funcionalidad. Según este primer concepto, la Trinidad consiste en expresar precisamente la "función que tiene Dios como asentador y fundamentador del mundo, de la verdad y de la vida religiosa del hombre" (PTHC 102).

El Nuevo Testamento tiene una riqueza enorme de textos que explican lo anterior. Por ejemplo, cuando se afirma del Padre que tiene la función de creador, de providente, de un legislador moral, etc. Al Hijo, en cambio, se le atribuye la función de ser revelador, redentor, de ser intercesor nuestro ante el Padre para hacernos hijos de Dios Padre. Y ambos unidos, Padre e Hijo, tienen como función enviar al Espíritu Santo. Este, por su parte, tiene como función santificar, iluminar, asistir a la Iglesia, residir en el alma del justo. Y este Espíritu Santo enviado por el Padre y el Hijo "tiene la función de ser un don del Padre por el Hijo" (PTHC 102).

Este es, pues, "el primer momento estructural de la revelación de un Dios trinitario: la revelación como fundamento y estructura formal de toda vida religiosa" (PTHC 102). 
Ahora bien, la funcionalidad trinitaria tiene, en primer lugar, un carácter individual. En efecto, el ser humano se dirige en su vida religiosa personal a Dios. En esta perspectiva, la eficacia de la oración depende de que recemos con Cristo al Padre, como el mismo Cristo lo dijo, según se afirma el Evangelio de san Juan: "Si pedís algo al Padre en mi nombre, os lo concederá" (Jn 16, 23) (PTHC 103)

La oración se dirige al Padre por el Hijo en el movimiento que nos lleva del Hijo al Padre, que es precisamente el Espíritu Santo ${ }^{28}$. La oración no puede dirigirse, pues, a esencia divina alguna. "Se reza al Dios Padre, por el Dios Hijo, en el Dios Espíritu Santo". En ese orden preciso se reza. Por tanto, la funcionalidad tiene este carácter de posibilitar una estructura muy precisa de la vida religiosa (PTHC 103).

La funcionalidad trinitaria tiene, en segundo lugar, un carácter histórico. No cabe duda de que desde los orígenes del monoteísmo, Dios ha actuado en la historia. En esta perspectiva es innegable que, al menos fragmentariamente, "el régimen del Antiguo Testamento es el régimen del Padre. En la vida de Cristo, tenemos el régimen del Hijo. Y en la Iglesia, el régimen del Espíritu Santo" (PTHC 104).

Ahora bien, la unidad de la revelación consiste justo en afirmar que "la revelación es una, en la que, en el Espíritu Santo, el Hijo nos lleva al Padre de una manera histórica. Es la unidad radical del movimiento del monoteísmo y de la divinización de la vía de la transcendencia" (PTHC 104) ${ }^{29}$.

La funcionalidad trinitaria tiene, en tercer lugar y finalmente, un carácter cósmico. En esta perspectiva, Zubiri dice que para san Pablo la "creación material está gimiendo por una transfiguración gloriosa" ( $c f r$. Rm 8, 19-22) (PTHC 104) ${ }^{30}$.

27. Sobre el tema de la oración en el contexto de la entrega en Zubiri, véase HD 199-200. Para la oración en clave trinitaria, véase J. Gamarra, "Oración”, en DTDC, 977-988.

28. En este contexto, Zubiri considera la "devoción" y la "oración" trinitaria de san Ignacio de Loyola, citando el número 28 de la Autobiografia, aparecida en sus Obras completas, Madrid, 1977, p. 107 ( $c f r$. PTHC, nota 1). Aquí merece la pena recordar la fundamental contemplación de la encarnación en clave trinitaria de Ignacio, plasmada en sus clásicos Ejercicios espirituales ( $c f r$ EE 102-109).

29. Sobre la vía de la transcendencia en Zubiri, véase PFHR 139-146. Una síntesis de esa vía puede verse en nuestro trabajo H. C. Gudiel García, La fe según Xavier Zubiri, óp. cit., pp. 229-230.

30. Nótese la parquedad con que Zubiri trata este punto. En Romanos 8, 19-22 se lee: "Pues la ansiosa espera de la creación desea vivamente la revelación de los hijos de Dios. La creación, en efecto, fue sometida a la caducidad, no espontáneamente, sino por aquel que la sometió, en la esperanza de ser libertad de la esclavitud de la corrupción para participar en la gloriosa libertad de los hijos de Dios. Pues sabemos que la creación entera gime hasta el presente y sufre dolores de parto" (NBJ). 
En definitiva, la funcionalidad trinitaria, en su primer estrato elemental, profundo y radical, atañe y concierne "a la vida religiosa individual, a la estructura de la historia de la revelación y a la estructura misma del cosmos respecto de Dios" (PTHC 104).

La funcionalidad es esencial en sí misma, y también lo es para una "intelección interna de la propia Trinidad" (PTHC 104).

La funcionalidad es un elemento fundamental en la "revelación del misterio trinitario y en la acción de la Trinidad". Obviamente, la Trinidad no consiste en tal funcionalidad, sin embargo, hay que afirmar al mismo tiempo que la Trinidad es funcional. Por tal razón, la exposición del concepto de funcionalidad debiera ser el preámbulo "de la teología trinitaria como fue la propia revelación”. Según Zubiri, "Dios no deja de funcionar como trino en ningún caso" (PTHC 107).

Por tanto, la funcionalidad es el primer "momento estructural de la revelación del misterio trinitario" (PTHC 107).

\subsubsection{La transcendencia de la Trinidad}

El segundo momento estructural de la revelación del misterio trinitario se expresa bajo el concepto de transcendencia (PTHC 107). En efecto, el Padre, el Hijo y el Espíritu Santo "en cuanto tales son anteriores a toda creación". En este sentido, puede afirmarse que "la Trinidad en cuanto tal transciende la creación del mundo". Ahora bien, ¿qué se entiende por transcendencia? (PTHC 108).

\section{a. La pretemporalidad de cada término}

Por ser anterior a toda creación, la Trinidad también es anterior al tiempo en que la creación formalmente consiste. Es lo que expresa obviamente la fe, y que luego se repetirá en el I Concilio de Constantinopla: "antes de todos los tiempos" (DH 150) (PTHC 108).

Esta anterioridad pretemporal pertenece a cada uno de los tres términos en su singularidad. Esto es lo fundamental. Precisamente en el Antiguo Testamento se nos presenta, por ejemplo, "la sabiduría de Dios como una Sabiduría personificada, que ciertamente no es la del Verbo, pues de ella se dice que es criatura: 'fui creada antes de todos los tiempos' (Si 24, 9; cfr. 1, 4.9; 24, 8; Pro 8, 22)". Sería imposible comprender "todas estas alusiones y exposiciones del Antiguo Testamento si no se anclan en la idea de una transcendencia transfuncional" (PTHC 108).

31. A continuación, Zubiri expone la idea de la funcionalidad trinitaria en relación con algunas herejías trinitarias como el modalismo ( $c f r$. 104-107). 
Ciertamente, el Evangelio de san Juan 1lama a Dios "Logos", pero el "Logos del que explícitamente ahí se trata es el Logos en tanto que revela a Dios. Es el Logos revelador". El prólogo del cuarto Evangelio afirma la transcendencia (PTHC 108). Es decir, afirma "que la revelación y el Logos vienen precisamente de algo que es anterior a todo tiempo y a toda creación" (PTHC 108-109).

Sea como fuere, en la personificación de la Sabiduría "hay una especie de barrunto de un término anterior a la creación. Lo propio debe decirse del Espíritu" (PTHC 109)

\section{b. Estructura interna de los tres términos}

Estos tres términos transcendentes (Padre, Hijo y Espíritu Santo) no están meramente yuxtapuestos, sino que tienen entre ellos una estructuración interna. El mismo Jesucristo afirma, según el cuarto Evangelio: "El Padre es mayor que yo" (Jn 14, 28). En esta perspectiva, Zubiri dice que Orígenes llama al Hijo

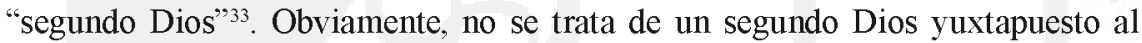
Padre, sino de un Dios de "segundo orden". Pero donde la expresión "orden" denota, por lo pronto, que el Hijo está "fundamentado" en el Padre. Lo mismo debe afirmarse del Espíritu Santo (PTHC 109).

Esta concepción de que los "tres términos tienen entre sí un rango y una reestructuración interna en este orden de lo transcendente es lo que ha producido una grave dificultad, que terminó en un error llamado subordinacionismo" (PTHC $109)^{34}$.

En todo caso, lo que para nuestro autor resulta fundamental y evidente en este segundo estadio es la transcendencia. En efecto, el Padre, el Hijo y el Espíritu Santo son más que la funcionalidad, son también algo que pertenece al orden transcendente. Este orden es divino y transcendente, en el que Dios tiene una función ( $c f r$. PTHC 110).

En la exposición de la teología trinitaria es fundamental considerar la transcendencia como distinta de la funcionalidad. Esta solo existe fundada en la transcendencia. Es decir, la funcionalidad solo existe "en la medida en que hay un orden divino que en una o en otra forma envuelve estos distintos términos debidamente estructurados en una estructura unitaria de rango distinto". De

32. La expresión "barrunto" significa, según la RAE, la "acción de barruntar". Y tal acción es definida como "prever, conjeturar o presentir por alguna señal o indicio".

33. Véase la fuente que cita Zubiri en PTHC 109, nota 1.

34. "Con el término subordinacionismo se designa una postura cristológico-trinitaria que tiende a hacer de Cristo una realidad inferior y subordinada a Dios Padre (y del Espíritu una realidad subordinada también a Cristo)". El subordinacionismo incluye las tendencias del arrianismo y del adopcionismo (S. del Cura Elena, "Subordinacionismo", en DTDC, 1311). 
lo contrario, no podría interpretarse la funcionalidad del Padre, del Hijo y del Espíritu Santo. La funcionalidad, pues, es transcendente (PTHC 111).

La funcionalidad no queda abolida, sino asumida en la transcendencia. Esto no significa que la Trinidad consista en la transcendencia. Esa fue precisamente la obra de Arrio respecto del Hijo (PTHC 112) ${ }^{35}$.

Algo similar ocurría años después con respecto al Espíritu Santo. En ese contexto surgieron los pneumatómacos, que consideraban que el Espíritu Santo "pertenecía al orden transcendente como una especie de gran ángel revelador de Dios, pero nada más" (PTHC 113)

Como consecuencia de ello, la "transcendencia de la Trinidad sería ciertamente una transcendencia de los tres términos respecto al mundo, pero no respecto de toda creación; serían tres términos absolutamente distintos, y toda su realidad física sería triplicidad: Dios y las dos realidades intermedias entre él y el mundo". Naturalmente, la Iglesia rechazó tal "interpretación en el concilio de Nicea y en el primer concilio de Constantinopla. La Trinidad es transcendencia a toda posible creación. La Trinidad no es 'causación', sino 'procesión'. Y, por tanto, es una verdadera Trinidad constitutiva de Dios en cuanto tal" (PTHC 113).

\subsubsection{La consustancialidad de la Trinidad}

Ahora bien, el Verbo y el Espíritu Santo no solo pertenecen al mundo divino, sino que su transcendencia es la estructura misma de Dios en cuanto tal. Es justo lo que se expresa con el concepto consagrado por el I Concilio de Nicea: consustancialidad (PTHC 114) ${ }^{37}$.

Pues bien, "funcionalidad, transcendencia y consustancialidad son los tres conceptos que expresan, de una manera progresiva, la penetración con que el hombre, por la revelación de Cristo, tiene acceso a la divinidad". Ese acceso "parte de la funcionalidad, llega a la transcendencia y se hunde en la realidad misma de Dios [...]. La transcendencia se funda en un orden estructural interno

35. A continuación, se explican las ideas de Arrio y se presenta un texto suyo en el que, según Zubiri, aparecen todos los elementos de su teología (cfr. PTHC 112-113). Sobre la doctrina de Arrio, puede verse también L. F. Ladaria, El Dios vivo y verdadero, óp. cit., pp. 177-182.

36. Congar expresa que “para los 'pneumatómacos', el Espíritu era una fuerza, un instrumento de Dios, creado para actuar en nosotros y en el mundo. Se permanecía en el plano de la 'economía'; se desconocía el de la 'teología', es decir, lo que supone, al nivel de Dios mismo y de su ser, la acción divinizadora en el hombre", Y. M. J. Congar, El Espiritu Santo, 103.

37. Sobre la importancia del símbolo de Nicea y el concepto de homoousios, véase L. Ladaria, El Dios vivo y verdadero, óp. cit., pp. 187-193. 
a Dios mismo" (PTHC 114). Con esto se comprende, dice Zubiri, lo que dice el Concilio de Nicea:

Creemos en un solo Dios, Padre omnipotente, creador de las cosas visibles e invisibles, y en su único Hijo Jesucristo, el Hijo de Dios que ha sido engendrado [...] como unigénito por el Padre, esto es, de la ousía del Padre, Dios de Dios, Luz de Luz, Dios verdadero de Dios verdadero, engendrado [...] y no creado, consustancial (homoousios) al Padre. ${ }^{38}$

La fórmula del Concilio de Nicea significa, según Zubiri, que la "Trinidad no es una efección causal, ni temporal ni eterna, en el orden transcendente, sino una misteriosa referencia de Dios a sí mismo. El Verbo está engendrado, pero no hecho o producido. El Espíritu Santo procede del Padre y del Hijo, o del Padre por el Hijo. Es una estricta Trinidad. Cada término es en algún momento suyo realmente distinto de los otros dos: los tres son necesariamente idénticos en ousía" (PTHC 115).

De esta manera, puede afirmarse que "la consustancialidad es el carácter y el fundamento último de la transcendencia. Es el punto preciso y formal del misterio trinitario" (PTHC 115) ${ }^{39}$. Por tal razón, es "el misterio de los misterios, porque es el misterio de la realidad misma de Dios en cuanto Dios" (PTHC 115-116). La consustancialidad funda la transcendencia. "Mientras la transcendencia consiste en afirmar que el Verbo y el Espíritu pertenecen al orden divino, la consustancialidad afirma el carácter de esta pertenencia y de este orden" (PTHC 116).

He aquí precisamente el contenido del dogma trinitario. En él se afirma, ante todo, la diferencia real y no simplemente "funcional" del Padre, del Hijo y del Espíritu Santo. También se sostiene "su perfecta unidad numérica en naturaleza: son consustanciales". Además, se declara que el Padre "engendra" al Hijo y ambos "espiran" al Espíritu Santo. Son "meras 'procesiones' y no producciones causales". Y, justo por ello, constituyen, finalmente, la Trinidad de un solo Dios (PTHC 116).

\subsubsection{El problema de los conceptos}

Ahora bien, Zubiri constata a continuación que existe una diferencia enorme de lenguaje y de conceptuación entre estos conceptos empleados en este momento del Concilio de Nicea y el contenido de la revelación neotesta-

38. DH 125; PTHC 114-115. La cursiva es nuestra.

39. "Sin duda ninguna con el símbolo de Nicea llegamos a uno de los puntos fundamentales, si no el decisivo, del desarrollo del dogma trinitario", L. F. Ladaria, El Dios vivo y verdadero, óp. cit., pp. 187-188. 
mentaria, donde jamás se habla de sustancia, mucho menos de consustancial ${ }^{40}$. Lo cual plantea varios problemas ineludibles para la inteligencia teológica (cfr. PTHC 116).

El primer problema radica en que, tanto en el texto revelado como en el Concilio de Nicea, jamás se habla del Padre, del Hijo y del Espíritu Santo como personas. El segundo problema que se pone de manifiesto consiste en el uso de los términos sustancia y consustancial. Esto no significa que Nicea haya canonizado el concepto de sustancia ( $c f r$. PTHC 117). El tercer problema surgido consiste en afirmar que el "Verbo está engendrado y no creado". ¿Qué significa ahí el término engendrado? (PTHC 119). Pues bien, como persona, como sustancia y como generación. He ahí tres cuestiones en donde aparece un "campo abierto" (PTHC 119).

Ahora bien, "¿cuál es la estructura interna de esta trinitariedad de la realidad divina?". Es el tema de la siguiente sección (PTHC 119).

\section{Conceptuación zubiriana del misterio trinitario}

En esta sección, Zubiri parte del supuesto de que en lo definido por el Concilio de Nicea se utilizan "conceptos de una filosofía determinada que luego no ha sido la única filosofía que ha imperado dentro de la teología, y que, por consiguiente, la teología posterior carece de unidad conceptiva" (PTHC 120). Esto quiere decir que hay una cierta amplitud para poder "tratar de conceptuar de alguna manera esta realidad trinitaria". Se trata de una "conceptuación de la vida personal de Dios tal como se nos ha revelado" (PTHC 120-121).

Supuesto lo anterior, se divide esta sección en los siguientes cuatro pasos sucesivos ( $c f r$. PTHC 121-122). Veamos el primero.

\subsection{La realidad formal del Padre, del Hijo y del Espíritu Santo}

Nuestro autor comienza recordando en esta primera cuestión que el concepto de persona aplicado a la Trinidad resulta "inadecuado" $"$. Y la razón de esto es que todos piensan que una persona es una realidad dotada de "inteligencia, voluntad, libertad, responsabilidad, etc.". En esta perspectiva, afirmar que el Padre, el Hijo y el Espíritu Santo son tres personas distintas es un "triteísmo" 2 . Ahora bien, como es difícil de evitar que la expresión persona tenga otro sentido,

40. Aquí Zubiri exceptúa el texto del Evangelio de Lucas 15, 12-13, donde sí se habla de sustancia, pero cuyo significado es más bien el de "patrimonio" (PTHC 116).

41. Una exposición sobre la problemática moderna del término persona, puede verse en L. F. Ladaria, El Dios vivo y verdadero, óp. cit., pp. 276-296. A. González dedica todo un capítulo al "concepto de persona" en su trabajo Trinidad y liberación, pp. 167-202.

42. Sobre este tema, véase S. del Cura Elena, "Triteísmo", en DTDC, pp. 1395-1400. 
se recurre a otro tipo de conceptos. Se afirma, por ejemplo, que lo peculiar de una persona es ser subsistente. Así, se habla de "tres subsistencias; son cada uno un subsistente" (PTHC 122) ${ }^{43}$. Pero si, por un lado, el concepto de persona conduce al equívoco del triteísmo, por el otro, el de subsistencia es prácticamente incomprensible (cfr. PTHC 122).

Zubiri, en cambio, piensa que el ser humano es una esencia abierta, abierta a su propio carácter de realidad. En virtud de ello, las propiedades que la realidad humana tiene, las tiene "de suyo" como realidad sustantiva. En esto consiste ser real. Pero además, justo porque tiene una nota intelectiva, el hombre está abierto a su propia realidad. Y gracias a ello, las propiedades que son "de suyo", son formal y doblemente "suyas" (PTHC 123).

El ser humano es persona precisamente en la medida en que es "suyo". Relativamente "suyo" porque él es un ser finito. Esta realidad relativamente absoluta demanda la existencia de una realidad "absolutamente absoluta" definitiva, aquí nos encontramos con que aquello que constituye propiamente el carácter de una persona es la suidad. Alguien es persona cuando es suyo, se pertenece a sí mismo: es suidad (PTHC 123) ${ }^{45}$.

En opinión de Zubiri, la suidad es la raíz de la subsistencia. En efecto, yo puedo afirmar que "soy subsistente en tanto que soy mío". La suidad funda la subsistencia. Lo que propiamente son el Padre y el Hijo es justo suidades. Lógicamente, tal suidad tiene un carácter muy particular. Mientras en el caso de la realidad humana la "suidad es algo consecutivo a ciertas propiedades y caracteres que el hombre tiene, en el caso de Dios es formalmente idéntico a aquello que es Dios" (PTHC 124) ${ }^{46}$.

Efectivamente, "hay una identidad entre la suidad y la esencia, que justamente es la raíz misma del misterio. La suidad no añade ninguna propiedad a la realidad; por eso puede identificarse con ella sin hacerla "compuesto". Pero "bien entendido que para la mente humana esta identidad es siempre una identificación". En otras palabras, se trata de dos conceptos diferentes. Sin embargo, "se los hace identificar por convergencia de un misterio". Según Zubiri, es necesario

43. Zubiri se refiere a la posición de K. Rahner sobre dicho tema (cfr. PTHC 122, nota 1). Una breve presentación del concepto de "subsistencia" en K. Rahner puede verse en L. F. Ladaria, El Dios vivo y verdadero, óp. cit., pp. 282-285.

44. Sobre este tema, puede verse HD 134-164 ( $c f r$. PTHC 123, nota 1).

45. Véase también A. González, Trinidady liberación, óp. cit., p. 188.

46. "Decir que Dios es persona no significa predicar de la realidad de Dios todos los caracteres físicos, biológicos, psicológicos, etc., que se predican de la realidad humana, sino solamente decir que la Realidad absoluta no puede menos de poseerse a sí misma" (ibid., p. 192). 
partir precisamente de la "suidad y tratar de ver qué puede ser eso que se llama la esencia divina. La primacía radical es la de la suidad" (PTHC 124).

La suidad no se refiere en modo alguno a un carácter psicológico, sino propiamente a un carácter absolutamente metafísico de la persona (cfr. PTHC 124). Pero además, "no es lo mismo la suidad que la realidad que es suya entera. Son cosas relativamente distintas. Yo tengo una suidad en virtud de la cual soy persona, pero a mi persona pertenecen justamente por razón de suidad todos los caracteres reales y efectivos que físicamente yo poseo". Y en este sentido, naturalmente, el Padre, el Hijo y el Espíritu Santo no son tres personas distintas. En este caso, "no son tres personas distintas más que por razón del carácter de su suidad, pero no por el carácter esencial" (PTHC 125).

En definitiva, a la suidad debe dársele "prioridad metafísica y teológica sobre aquello que constituye el complejo de los caracteres físicos que componen la persona". De ahí que cabe preguntarse en qué consiste una "procesión". Es el segundo paso por esclarecer (PTHC 125).

\subsection{El orden procesual de la realidad trinitaria}

En esta segunda cuestión, se parte de la afirmación de que las personas "proceden" unas de otras. Y se añade que "el Hijo procede del Padre y el Espíritu Santo procede del Padre y del Hijo". Ahora bien, ¿qué significa "proceder"? (PTHC 125).

La procesión ha sido entendida como una operación que se ejecuta. Pero procesión también ha significado "cosa operada". Ahora bien, es innegable para Zubiri que esta concepción de la procesión parte de un supuesto muy discutible. En efecto, tanto en el primero como en el segundo caso, se parte de que la actividad es una "operación ejecutada". Pero la cuestión es distinta, ya que para nuestro autor toda realidad, por el mero hecho de serlo, y en cuanto real, es en sí misma y por sí misma activa. $\mathrm{Y}$ en este caso, la actividad no es una operación, sino un "dar de sí" (PTHC 126)

Dar de sí precisamente por ser real. "Este dar de sí es modo activo por razón de su propia realidad, la plenitud de aquello que constituye esa misma realidad" (PTHC 126-127). "En la medida en que la realidad es formalmente un dar de sí aquello que en sí misma y por sí misma es, la actividad no es un momento consecutivo a la realidad, sino algo formalmente constitutivo de la realidad en cuanto tal" (PTHC 127).

Pues bien, en este sentido, Zubiri dice que no debe excluirse a Dios de la procesión, sencillamente porque actividad es procesión. Esto deja intacto un

47. La tesis central de la obra póstuma de Zubiri, Estructura dinámica de la realidad, afirma precisamente que la realidad "da de sî" (D. Gracia, "Presentación", pp. iv-v). 
momento fundamental "en la concepción de la vida trinitaria: la vida de Dios". "Es la propia actividad divina, que no está integrada por operaciones que 'ejecuta', sino que es la plenitud infinita de la realidad que formalmente es en tanto que en y por sí misma es activa" (PTHC 127).

Supuesto lo anterior, cabe preguntarse enseguida: “¿cuál es la estructura procesual de las procesiones y de las personas en la Trinidad?" (PTHC 127). Es lo que toca responder a continuación.

\subsection{Estructura procesual de la Trinidad}

Ante todo, recordemos que lo que conforma el carácter propio de la Trinidad es la suidad. En consecuencia, afirmar que en Dios "hay un Padre, un Hijo y un Espíritu Santo realmente distintos significa que en Dios hay tres suidades realmente distintas". Esto quiere decir, en otras palabras, que "Dios es realmente suyo de tres maneras realmente distintas" (PTHC 128).

Las tres suidades en Dios son "radical y últimamente distintas, solamente que las tres son suidades de alguna manera". La suidad no es algo unívoco, sino análogo. Es distinta la suidad del Padre, la del Hijo y la del Espíritu Santo. Y en esta Trinidad de suidades hay que centrar la atención para aclarar "en qué consiste la procesionalidad activa de la realidad divina en cuanto tal" (PTHC 128).

\subsubsection{El Padre: principio de la Trinidad}

El punto de partida en esta cuestión es aquello que para Zubiri forma parte del texto revelado, según el cual el "principio" de la Trinidad es el Padre. Él, y no la esencia, es el principio de la Trinidad (PTHC 128). Por esa razón, el Padre es quien constituye el monos del monoteísmo. En efecto, el "monoteísmo cristiano es Dios Padre como principio uno y único de la Trinidad toda y del mundo" (PTHC 129).

En este contexto, recordemos que la justificación zubiriana de la realidad de Dios consiste en pasar de la realidad personal relativamente absoluta a la realidad absolutamente absoluta: precisamente la realidad de Dios (cfr. PTHC 129) ${ }^{48}$.

Esta realidad absolutamente absoluta es, en primer lugar, "una realidad que por ser absolutamente absoluta es radical y últimamente suya: tiene una suidad". Y por tal razón podemos y debemos afirmar que es "Padre". Obviamente, aquí no se trata de probar racionalmente que la "suidad de la realidad absolutamente absoluta consiste en ser formalmente Padre: esto sería probar la Trinidad racio-

48. Sobre el tema, puede verse HD 134-164 ( $c f r$. PTHC 129, nota 1). En este contexto también puede verse la minuciosa obra de J. M. Millás, La realidad de Dios, Roma, 2004, en concreto las pp. 102-122. 
nalmente". Se trata más bien de afirmar que la "realidad que desde el punto de vista de la fe es Padre, tiene justamente una suidad". En efecto, "por la fe sabemos que esta suidad es formalmente paternidad (PTHC 129).

En segundo lugar, recordemos que el único modo posible de que una realidad absolutamente absoluta tenga suidad es que sea "inteligente y volente" ${ }^{\text {. }}$. De ello se desprende y se sigue que la realidad absolutamente absoluta con suidad de Padre es inexorablemente "inteligente y volente". Con lo cual se quiere clarificar que el hecho de que Dios Padre "sea inteligente y volente no es el principio de la procesión, sino justamente al revés: en cierto modo, el resultado". Justo porque el Padre es suyo, por eso es "inteligente y volente". En otras palabras, la prioridad corresponde radicalmente a la suidad (PTHC 129).

Por tanto, ante la pregunta quién es el Padre, cabe responder que "es la suidad de la realidad absolutamente absoluta". Y ante la cuestión qué es esta realidad absolutamente absoluta, hay que contestar que es una realidad inteligente y volente (PTHC 130).

En tercer lugar, este qué de la realidad absolutamente absoluta es una realidad abierta en dos sentidos. En sentido personal, la suidad del Padre en cuanto suidad está "abierta a dar de sí la suidad del Hijo. La estructura de esta apertura es justo la procesualidad en cuanto tal" (PTHC 130).

En sentido esencial, en cambio, la suidad del Padre es inteligente y volente. En virtud de ello, el Padre es esencia abierta. Entonces, "mientras la apertura de suidad es personal, la apertura de inteligencia y voluntad es esencial". Ambas aperturas unidas constituyen el carácter de "éxtasis". El Padre, pues, es realidad "extática" (PTHC 130).

49. Vale la pena recoger en este momento lo que hemos sintetizado de Zubiri en otro lugar: "La autoposesión es 'actualidad absoluta para sí mismo'. Esta actualidad lo es, ante todo, en el sentido de ser 'presencia de la realidad a sí mismo'. Tal actualidad es lo que constituye la 'inteligencia'. En virtud de ella la vida divina es 'vida en inteligencia'. Y como la actualidad de lo real en la inteligencia es 'verdad real', consecuentemente puede afirmarse que "la vida divina consiste en ser su propia verdad real'. Cabe notar además que la autoposesión es esencialmente posesión, es decir, es 'fruición'. Fruición es el reposo en la plenitud de la propia realidad. La actualidad en cuanto fruición es lo que Zubiri llama 'voluntad'. En esta voluntad se consuma la 'plenaria suidad' de la realidad absolutamente absoluta (HD 169)'.

"De lo anterior se desprende que Dios "es necesariamente inteligente y volente porque es suidad absoluta, porque es persona'. La concreción de la realidad personal de Dios consiste en ser 'vida absoluta'. Y 'la concreción de la vida absoluta es inteligencia y voluntad'. Inteligencia y voluntad son momentos intrínsecos de la realidad sustantiva de Dios (HD 170)". Véase H. C. Gudiel García, La fe según Xavier Zubiri, óp. cit., p. 114. 
Desde la apertura esencial, el Padre es una esencia abierta justo porque posee una inteligencia. La inteligencia está totalmente abierta, por su propia condición, "al carácter de realidad de aquello que la inteligencia aprehende". De lo cual se desprende que la inteligencia lleva a una situación particular en el Padre, en virtud de la cual la realidad del Padre (el "quién") "es algo que no está poseído en actualidad sino de una manera abierta" (PTHC 130). Esta realidad actual en cuanto realidad (actualidad de la realidad que es la propia esencia del Padre) es "principio y fuente" del Hijo y de la vida trinitaria (PTHC 131).

En definitiva, lo fundamental en este momento es afirmar que esa realidad es una realidad que es absolutamente suya, en el sentido de que es "fuente y principio de sí misma" (PTHC 131).

\subsubsection{El Hijo: suidad de la verdad real del Padre}

Ahora bien, lo propio de la inteligencia consiste en que en ella aquello que es inteligido cobra actualidad $^{50}$. Es decir, lo inteligido en cuanto inteligido es la mera actualidad de lo real. En la inteligencia, pues, aquello que está inteligido pura y simplemente está actualizado (PTHC 131) ${ }^{51}$.

\section{a. La verdad real}

En primer lugar, esta actualización es lo que da a la realidad inteligida su carácter de verdad. Desde esta perspectiva, verdad es primariamente la mera actualidad de lo real en la inteligencia. Por esto se trata, en rigor, de la "verdad real" ${ }^{\prime 2}$. Ahora bien, actualidad no es idéntica a realidad, por eso no es lo mismo verdad que realidad ${ }^{53}$. Pero en el caso de que haya verdad o actualización, lo propio de la inteligencia es precisamente tener "verdad real" (PTHC 131).

Aquí cabe recordar que lo primero es que la "suidad del Padre constituye la realidad inteligente y volente" (PTHC 131). Y, gracias a ello (aquí es donde aparece el misterio), hay una "segunda suidad". Esta es distinta de la suidad del Padre, "en virtud de la cual su realidad es plenariamente absolutamente absoluta". Pero es suidad distinta: es la suidad de la verdad en cuanto verdad. En

50. Sobre este concepto clave de actualidad como esencia de la intelección, véase la obra de madurez de Zubiri IRE 133-168. También H. C. Gudiel García, La fe según Xavier Zubiri, óp. cit., pp. 37-47; y M. Mazón, Enfrentamiento y actualidad, pp. 193-264.

51. Naturalmente, la mera actualización no es lo único, pero es el punto de partida desde el cual se explican otras reactualizaciones en Zubiri.

52. Sobre este otro concepto fundamental de Zubiri, puede verse IRE 229-241. Véase también H. C. Gudiel García, La fe según Xavier Zubiri, óp. cit., pp. 56-62.

53. A continuación, Zubiri hace una anotación fundamental, clarificando que "hay realidades que no son actuales en ninguna inteligencia" (PTHC 131). 
esta perspectiva, Zubiri dice que para Ireneo el Hijo es la "definición" del Padre $(\mathrm{PTHC} 132)^{54}$.

\section{b. Verdad real actual del Hijo}

Y por eso, en segundo lugar, hay una íntima "implicación entre esta verdad real actual [el Hijo] y aquello que ha constituido la realidad del Padre". En efecto, la "actualidad de la verdad envuelve numéricamente la misma realidad que la realidad de lo actualizado en ella". Esto quiere decir que "aquello en que se realiza el Hijo es numéricamente idéntico a aquello que constituye la realidad del Padre". En otras palabras, el Padre y el Hijo son "consustanciales" (PTHC 132).

De esta manera, la consustancialidad es en cierto modo resultado de la procesión y no su principio. Porque hay la suidad de una verdad real, hay efectivamente una consustancialidad, una "coesencialidad". No es la consecuencia de una comunicación procesual, sino la condición ineludible de toda verdad real, con tal "que a la verdad real se le dé (y aquí está el misterio) un carácter de suidad realmente distinto". En cuanto realidad sustantiva, la realidad del Hijo "es numéricamente idéntica a la del Padre". Pero en cuanto "actualidad en suidad", el Padre y el Hijo son realmente distintos (PTHC 132).

Resumiendo: puede afirmarse que "el Padre da de sí una segunda suidad realmente distinta de la suya propia. Y esta segunda suidad es suidad de verdad". Gracias a ello, "el 'qué' de esta segunda suidad es numéricamente idéntico al 'qué' de la primera: son consustanciales". Lo radical consiste en que el Padre da de sí una segunda suidad, y que ésta "se realiza en la misma esencia que aquélla en que se realiza la suidad del Padre. Que el Padre dé de sí esta segunda suidad qua suidad es el misterio". En opinión de Zubiri, esta procesión "es directa y formalmente una procesión de persona (Padre) a persona (Hijo)" (PTHC 133).

\section{c. La generación del Hijo}

Ahora bien, en tercer lugar, en todo el Nuevo Testamento se afirma de la realidad del Hijo, y lo repite luego el Concilio de Nicea, "que está engendrada: es el problema de la generación" (PTHC 133).

No olvidemos en este contexto que el Padre, el Hijo y el Espíritu Santo tienen, cada uno de ellos, una función determinada en la vida religiosa del ser humano. Y que Jesucristo es "Hijo de Dios". En consecuencia, la filiación recae "directa, formal y explícitamente sobre la realidad de Jesucristo sobre la tierra, en tanto que Hijo de Dios". Pero lo cierto "es que el "engendrado', aunque esté en todo el Nuevo Testamento, sin embargo sólo se refiere [...] al Verbo encarnado" (PTHC 134).

54. Cfr. PTHC 132, nota 1. 
La generación "no es el carácter formal y primario de la procesión" (PTHC 134). En opinión de Zubiri, el carácter generacional tan solo significa "que aquello en que se realiza el 'contenido' de la procesión es precisamente la transmisión o comunicación de una naturaleza idéntica desde el primer término de la procesión". Y en este sentido es "generación". En consecuencia, "la generación es generación porque hay procesión del Verbo", y no al revés (PTHC 135).

Nuestro autor afirma que la "procesión del Hijo es generación porque es una procesión filial y no al revés". Esa misma procesión del Hijo "es generación pura y simplemente porque procede, como suidad distinta, de un Padre que le es consustancial, que es consustancial a la verdad real". La procesión apunta directamente a la consustancialidad; a la generación apunta solo indirectamente. De esta manera, pues, "el Padre, como realidad suya principal, da de sí su verdad real y, por tanto, comunica a la verdad la suidad de su propia naturaleza, es decir, es una generación" (PTHC 135).

Además del Padre y del Hijo, hay que decir algo sobre el Espíritu de la Verdad.

\subsubsection{EI Espíritu de la Verdad}

Aquí Zubiri comienza considerando que, en el caso concreto de mi realidad humana, sucede que yo tengo mi realidad actualizada, pero además la tengo actualizada en mi inteligencia. Ahora bien, "esto que en el caso del hombre no pasa de ser un aspecto de la intelección, es en el caso de Dios algo distinto" (PTHC 135).

Es algo diferente porque, tratándose de Dios, no solo "hay lo que hay en el hombre, a saber: el sentido de que la verdad real, en una o en otra forma, se identifica con la realidad de la que es actualidad en la inteligencia, sino que es algo más". Es algo distinto: es el Espíritu de la Verdad, como lo llama san Juan $(\mathrm{Jn} 16,13)^{55}$. Y el carácter de este Espíritu consiste en "ratificar la identidad de la verdad con la realidad" (PTHC 136).

El Padre "es la suidad de la realidad en cuanto principio. Actualizado en la verdad real que constituye su Hijo es la suidad de la realidad en cuanto verdad. Y esta verdad real expresa por identidad la realidad radical y primaria, la realidad 'árquica' que constituye la realidad del Padre". Esta identidad es precisamente el Espíritu de la Verdad. Desde la perspectiva de la fe, puede afirmarse, entonces,

55. Estas cursivas son nuestras. El versículo completo de san Juan 16, 13 dice: "cuando venga él, el Espiritu de la verdad, os guiará hasta la verdad completa; pues no hablará por su cuenta, sino que hablará lo que oiga, y os lo explicará a vosotros"; la cursiva es nuestra. En $N B J$. 
que es una "tercera suidad: el Espíritu Santo". Pues bien, "el Espíritu Santo como suidad es la actualidad de la identidad de la verdad y de la realidad" (PTHC 136).

De lo anterior se desprenden algunas preguntas. En primer lugar, " $\mathrm{y} y$ por qué no es generación la procesión del Espíritu Santo?". Por una razón compleja, pero que es evidente en cierto modo. En efecto, para que haya generación de la suidad, tiene que haber una comunicación de una realidad, aunque sea por vía de identidad: "solamente entonces hay generación" (PTHC 136).

Ahora bien, esto no puede suceder en el Espíritu Santo porque toda la realidad está "ya dada en la verdad real que constituye el Hijo, y por consiguiente no hay nada que comunicar". 'Lo único que se puede hacer es 'ratificar' la identidad de la realidad comunicada de la verdad con la nuda realidad que constituye el punto de partida". En consecuencia, eso no es una generación, sino una "ratificación" $\left(\right.$ PTHC 137) ${ }^{56}$.

Si lo anterior es así, cabe preguntarse en segundo lugar, "quién es el que espira esa tercera suidad". La respuesta es clara: "El Espíritu de la Verdad que consiste en la identidad de la verdad y de la realidad primera 'procede' (y ahí está el término) como segundo momento procesional de aquellos dos términos que he identificado: es justamente la procedencia del Espíritu Santo del Padre por el Hijo". La teología latina lo difundió "con su célebre fórmula del Padre 'y' del Hijo (Filioque)". Tal fórmula tiene sus limitaciones (PTHC 137) ${ }^{57}$.

Sea como fuere, "el Espíritu Santo es del Padre por el Hijo". En consecuencia, el Espíritu Santo "tiene la unidad de un principio de espiración, que es justamente la realidad unitaria que es realidad arjé en el Padre y es verdad real en el Hijo. Y, por esto, porque el 'qué' de Dios no está dado al Espíritu Santo, sino que esa ratificación acontece sobre un 'qué' dado al Hijo, es por lo que no es generación" (PTHC 137).

Ahora bien, en tercer lugar, de igual modo que la suidad del Padre se realiza inevitablemente como realidad absolutamente absoluta "en un 'qué' inteligente y volente; de la misma manera que la suidad de la verdad real se realiza en un 'qué' que está procedido por generación, la espiración del Espíritu Santo como ratificación de la identidad de la verdad en acto con la realidad primera no es ajena a esa esencia, a ese "qué"' (PTHC 137).

56. Sobre la idea de ratificación de la verdad real y los modos de ratificación, puede verse IRE 233-238, 240-241.

57. Sobre esta problemática, véase NHD 490-491 (cfr. PTHC 137, nota 1). Sobre el Fitioque y sobre la situación del tema en la actualidad, véase L. F. Ladaria, El Dios vivo y verdadero, óp. cit., pp. 355-364; y A. González, Trinidad y liberación, óp. cit., pp. 157-162. 
Según nuestro autor, la esencia en el Espíritu Santo "no está ni comunicada ni recibida, sino determinada a un momento esencial suyo: la fruición de la verdad". El Espíritu de la Verdad es precisamente el "término de una fruición, el término del amor. El amor, lo mismo en el mundo que en Dios, vive constitutivamente de realidad". Desde esta perspectiva zubiriana, la procesión del Espíritu Santo no es una procesión de amor, sino que propiamente es una "procesión por el Espíritu de la Verdad". El amor es ineludiblemente la consecuencia del Espíritu de la Verdad (PTHC 138).

Ciertamente, para Zubiri, el Espíritu Santo es amor, pero al mismo tiempo precisa que no es Espíritu Santo por ello, sino que es amor porque es Espíritu de la Verdad. Por tal razón, la "fruición está determinada por el Espíritu de la Verdad". La teología clásica parte de la "procesión por vía del amor y siempre ha tropezado con la frase joánica de que 'Dios es amor' (1 Jn 4, 8)". Sin embargo, cabe pensar lo contrario y partir desde la perspectiva del mismo san Juan, quien ha comenzado por nombrar al Espíritu Santo el "Espíritu de la Verdad" (PTHC 138)

De esta manera queda presentado, en palabras, lo que es el misterio de la Trinidad. La Trinidad es, efectivamente, "una suidad absolutamente absoluta, el Padre, que da de sí la suidad como actualidad de su verdad real (ese es el Hijo) y que ratifica en suidad la identidad de esa verdad real con el principio de donde procede, y en esa ratificación consiste el Espíritu de la Verdad, el Espíritu Santo". Un Espíritu que es Espíritu de Verdad, y por ello es principio de amor (PTHC 138).

\subsection{La vida trinitaria de Dios}

Después de lo dicho sobre la estructura procesual de la realidad divina trinitaria, cabe preguntarse a continuación ¿qué es eso que pudiéramos llamar la vida trinitaria de Dios? (cfr. PTHC 139).

Acostumbrados a oír la fórmula del bautismo: el Padre "y" el Hijo "y" el Espíritu Santo, uno cree que se trata de una "y" copulativa. Sin embargo, Zubiri piensa que no es ese carácter "de la ' $y$ ' lo que constituye la estructura formal de la realidad trinitaria de Dios, sino que hay una estructura, un rango intrínseco e interno entre esos términos que están tan sólo aparentemente copulados en la ' $\mathrm{y}$ "' (PTHC 139).

Conjeturando sobre la posibilidad de que esto pueda ser así, recordemos lo que sucede en el caso del hombre. Cada ser humano es siempre el mismo, pero nunca es $l o$ mismo $^{59}$. En el caso concreto de Dios, en cambio, sucede rigurosamente lo contrario: siempre es lo mismo, pero nunca es el mismo. Por lo menos,

58. Cfr. Juan 16, 13.

59. "Personalidad es la cualificación campal de la personeidad. Por esto yo soy siempre el mismo (personeidad), aunque nunca soy lo mismo (personalidad)" (IRE 273). 
Dios es tres veces distinto, y sin embargo, Dios es lo mismo. "Este 'mismo' es siempre completamente otro". Esto significa, naturalmente, que "esa ' $y$ ' no tiene un carácter meramente copulativo" (PTHC 139).

Todo lo contrario: en las procesiones trinitarias cada una de las suidades "está constituida por una intrínseca respectividad a las demás personas". En este sentido, puede afirmarse que "no hay Padre si no es habiendo un Hijo. Ni hay un Padre y un Hijo si no es espirando un Espíritu Santo". Se da, pues, una interna respectividad constitutiva de la procesualidad misma de las personas divinas en cuanto tales (PTHC 140).

Pues bien, preguntarse en qué consiste esta vida trinitaria significa interrogarse "en qué consiste esta respectividad, que en cierto modo (ahí está otro de los aspectos del misterio) unifica la vida trinitaria en Dios" ${ }^{\prime \prime 6}$. A esta cuestión puede responderse con los siguientes tres conceptos (PTHC 140).

\subsubsection{Implicación de personas}

La teología latina afirma que "el primer carácter de las personas es que empiezan a oponerse entre sí". Esta teología insistió en que las "personas son relativas, es decir, que la una es correlativa a la otra". La teología griega, por su parte, introdujo la noción de perijoresis ${ }^{61}$. Y esta fue entendida como una especie de circulación de la "esencia de Dios del Padre al Hijo, y del Hijo al Espíritu Santo, y así sucesivamente" (PTHC 140). "Es la misma esencia, que se mantiene idéntica, pero es 'comunicada' al Padre, al Hijo y al Espíritu Santo" (PTHC 141).

Sin negar la verdad de lo anterior, Zubiri piensa que la perijóresis no es el carácter formal de la respectividad trinitaria. Y argumenta que la respectividad trinitaria no es cuestión de perijóresis de naturaleza, sino de implicación de suidad. Es decir, de implicación de los "caracteres personales de la persona en cuanto tal". Es precisamente la "respectividad interna de las suidades en cuanto tales: del Padre en cuanto Padre, del Hijo en cuanto Hijo, y del Espíritu Santo en cuanto Espíritu Santo. Es decir, es un momento de suidad" (PTHC 141).

Indiscutiblemente, hay para nuestro autor una circulación de naturaleza. sin embargo, esta se da como "consecuencia de esta unidad estructural de las personas". En la medida en que cada persona envuelve "a las demás se puede hablar de una circulación de aquello que es la primera persona con aquello que es la segunda y aquello que es la tercera" (PTHC 141).

60. Sobre el tema de la respectividad, véase "Respectividad de lo real", Realitas, II-IV (1979), pp. 13-43.

61. Sobre este término, véase $\mathrm{S}$. del Cura Elena, "Perikhóresis", en DTDC, pp. 1086-1094. 
Los latinos, por su parte, tradujeron la expresión griega de perijóresis por circumincesión. Pero más bien la llamaron circuminsesión, con lo cual trivializaron "el concepto y el vocablo, porque entonces ya no es que una persona circule por las demás, sino que la una está en la otra". Esta diferencia es radical, concierne al concepto de "procesión". Personalmente, Zubiri piensa que es una "procesualidad en virtud de la cual las personas se implican entre sí en tanto que personas". Dios es un dar de sí absoluto, y da de sí. Cada suidad da de sí la otra, y además las tres suidades dan de sí una esencia única (PTHC 141).

\subsubsection{Compenetración de las personas}

Además de implicación de personas, en cierta manera también hay una circulación desde la perspectiva de la naturaleza. Pero es una circulación especial y curiosa a la que Zubiri llama la compenetración (PTHC 141).

Desde la perspectiva de la suidad, puede afirmarse que en la Trinidad hay una "compenetración interna en virtud de la cual aquello que es el Padre es justamente aquello que es el Hijo. Y el Padre ve, en cierto modo, por la inteligencia del Hijo, como el Hijo es lo que es viendo aquello que ha actualizado la inteligencia del Padre". Hay una estricta compenetración, y esta no es sencillamente una circulación (PTHC 142).

Si partimos de la persona, o la suidad del Padre, habría que decir que no es que la esencia de Dios no sea acto puro, sino que la pureza del acto de Dios "está constituida por la procesualidad trinitaria de sus personas" (PTHC 142).

En efecto, la pureza del acto, según el filósofo, "está misteriosamente constituida por la Trinidad procesual en que las personas consisten. Dios se realiza, se auto-realiza en acto puro en y por la Trinidad procesual de las personas". En opinión de Zubiri, el acto puro "es un carácter que misteriosamente no puede constituir el punto de partida de la teología trinitaria, sino que es, en cierto modo (humanamente hablando), el precipitado de esa maravillosa procesualidad trinitaria en que consiste justamente la suidad divina, en sus tres suidades: ser suyo como realidad fontanal, ser suyo como verdad actual, y ser suyo como idénticamente verdad y realidad en el Espíritu de la Verdad". Esto es así porque la persona es quien funda a la esencia, y no al revés. La procesión es propiamente personal. En consecuencia, para Zubiri la "unidad es unidad que está en cierto modo decantada en la constitución del acto puro en que consiste la esencia divina" (PTHC 143).

\subsubsection{La vida personal de Dios}

Además de la implicación y la compenetración en la Trinidad, tenemos un tercer aspecto fundamental. Y es que las tres personas también tienen una unidad que no es numérica, sino que consiste en la vida personal de Dios (PTHC 143). 
El término "vida" puede tener dos sentidos. Ante todo, puede significar un "acto que procede de la naturaleza, de la esencia" (PTHC 143). En este caso, obviamente, "en Dios no hay más que una vida, y además idéntica en las tres personas, justo como su propia esencia" (PTHC 143-144).

Pero la vida también puede entenderse desde la perspectiva personal. En este segundo sentido, la vida personal no se compone exclusivamente de una persona. Al contrario, la "plenitud de la vida personal de Dios está compuesta por varias personas. $\mathrm{Y}$ entre las varias personas, personalmente distintas, constituyen una sola vida personal que no es numéricamente una, pero sí tiene una unidad intrínseca de respectividad" (PTHC 144).

Este segundo sentido es lo que sucede en el caso concreto de la Trinidad. Misteriosamente, no por una unidad numérica, sino por el "carácter procesual en que estas personas se implican y se compenetran en su esencia, la vida de Dios [...] es una vida 'una' que es trinitariamente personal". Existe en Dios una unidad que no es unidad numérica, sino unidad de "personas que en su distinción constituyen una sola vida trinitaria, que es real y efectivamente la vida de Dios" (PTHC 144).

En efecto, "en Dios hay una vida, una unidad puramente respectiva y no numérica". Y en modo recíproco puede decirse que "la vida personal divina en la Trinidad misma está esencialmente vivida en tres personas distintas". "En Dios hay una vida trinitaria 'una' que tiene esta estructura en cierto modo unitaria, con unidad de respectividad". Efectivamente, "el Padre no es el Hijo como suidad, ni el Hijo y el Padre son el Espíritu Santo como suidad". Sin embargo, "ninguno de los tres puede existir y ser quien es sino es haciendo proceder al otro". Y esta es, dice Zubiri, "una actividad que tiene una unidad de respectividad, y esa unidad de respectividad es lo que a mi modo de ver constituye la vida trinitaria de Dios" (PTHC 144).

La vida de Dios es primaria y formalmente "una vida trinitariamente personal que se decanta en la propia esencia divina bajo la forma de un acto puro. Esta vida divina tiene un carácter modal: lo que suele llamarse eternidad". Pero aquí se advierte que este vocablo es equívoco, porque "sugiere lo que es y será desde 'toda la eternidad'. Es la duración insondable de Dios". Sin embargo, para Zubiri hay algo anterior y radical. En efecto, "todo lo que Dios hace y es lo es en modo eternal. Eternidad es el concepto modal de la vida divina. Y, si es durativamente eterno, es como consecuencia de ser modalmente eternal" (PTHC 145).

\section{Conclusión}

Es el momento oportuno de recoger, en modo sintético, algunos de los aspectos más significativos de esta exposición. Y también la ocasión pertinente para hacer una breve valoración, y para presentar la perspectiva que se abre con respecto al misterio de Dios en Zubiri. 
En primer lugar, el concepto de Trinidad aquí expuesto queda así ubicado en la amplia y global exposición y preocupación de Zubiri por el problema teologal del hombre, que incluye la cuestión de Dios, de las religiones y del cristianismo. Pero también clarificamos que el interés en este trabajo era presentar, en modo descriptivo, la concepción zubiriana sobre la revelación del misterio de Dios aparecida en su obra El problema teologal del hombre: Cristianismo. Es ahí donde el filósofo vasco se enfrenta en modo sistemático con los "grandes temas de la teología" ${ }^{92}$.

En segundo lugar, el cristianismo es una plasmación de la religación en la entrega del hombre a Dios. Desde esta religión, se accede a Dios por el mismo Dios. El cristianismo es obra de Cristo, pero también es obra histórica y obra del Espíritu Santo. De ahí que por historia, doctrina y espiración, la obra de Cristo es el cristianismo. Para el cristianismo, Dios es un misterio absoluto, pero ese misterio no es algo oscuro, sino que derrama su luz sobre todas las cosas reales.

En tercer lugar, desde la perspectiva del misterio de Dios en la revelación, hay un mismo Dios con tres términos, que constituyen la Trinidad. La revelación de la Trinidad es un movimiento progresivo, en virtud del cual la Trinidad se va mostrando en distintos aspectos y estadios. Son tres estadios que responden a tres conceptos esenciales. El primero, la funcionalidad trinitaria; el segundo, la transcendencia de la Trinidad. La funcionalidad está fundada en la transcendencia; por eso, aquella es transcendente. Finalmente, el estadio de la consustancialidad de la Trinidad, que aparece como el fundamento último de la transcendencia. La consustancialidad es el punto exacto y propio del misterio trinitario.

En cuarto lugar, desde la conceptuación propiamente zubiriana del misterio de Dios, la realidad formal del Padre, del Hijo y del Espíritu Santo consiste en ser una suidad particular. Esta tiene prioridad metafísica y teológica. Desde aquí se abordó el orden procesual de la realidad trinitaria. La procesión hay que entenderla desde la constitutiva actividad de la realidad; toda realidad, en cuanto real, es en sí misma y por sí misma activa. La actividad es un "dar de sí". Por eso, la actividad es algo constitutivo de la realidad en cuanto tal. Pues bien, actividad es procesión.

En la estructura procesual de la Trinidad, el Padre es principio de la Trinidad; es la suidad de la realidad absolutamente absoluta, inteligente y volente. Y por eso, es una realidad abierta en sentido personal y esencial. Por ambas aperturas, el Padre es una realidad extática. La realidad actual del Padre en cuanto realidad es principio y fuente del Hijo y de la vida trinitaria.

El Padre da de sí misteriosamente la suidad del Hijo. Es la segunda suidad. En cuanto realidad sustantiva, la realidad del Hijo es numéricamente idéntica a

62. A. González, La novedad teológica de la filosofía de Zubiri, óp. cit., p. 3. 
la realidad del Padre. Pero en cuanto actualidad en suidad, el Padre y el Hijo son realmente distintos. Por tanto, el Hijo es la suidad de la verdad real del Padre.

El carácter del Espíritu de la Verdad consiste en ratificar la identidad de la verdad con la realidad primera. Desde el punto de vista de la fe, el Espíritu Santo es una tercera suidad y, en cuanto tal, es la actualidad de la identidad de la verdad y de la realidad. El Espíritu de la Verdad procede del Padre por el Hijo, o del Padre "y" del Hijo. La procesión del Espíritu Santo es propiamente una procesión por el Espíritu de la Verdad. Por eso, el Espíritu de la Verdad, y justo por serlo, es principio de amor. El Espíritu Santo, pues, es Espíritu de amor porque es Espíritu de la Verdad. La esencia del Espíritu Santo está determinada por la fruición de la verdad.

El carácter formal de la respectividad trinitaria consiste en la implicación y la compenetración de personas. Pero las tres personas en su distinción también tienen una unidad: es la vida personal de Dios. Recíprocamente, esta vida divina está vivida en tres personas distintas. Por eso, en Dios hay una vida "una" que tiene esta estructura en alguna manera unitaria, con unidad de respectividad. En efecto, el Padre, el Hijo y el Espíritu Santo son distintos en cuanto suidades, pero ninguno de los tres puede existir y ser quien es sino haciendo proceder al otro. Esta actividad tiene una unidad de respectividad, y esa unidad es lo que constituye la vida trinitaria de Dios.

Estos son, a mi juicio, los rasgos más significativos, novedosos y sugerentes surgidos en la conceptuación zubiriana del misterio de la Trinidad, en el trabajo aquí expuesto.

Considero un mérito indiscutible de Xavier Zubiri el intento por abordar en modo original el tema de la revelación del misterio del Dios uno y trino, desde la perspectiva de su propia filosofía. Y lo ha hecho no en modo aislado, sino en el amplio contexto de su interpretación global de la religión cristiana y de su propio pensamiento filosófico. Esa interpretación global del cristianismo "incluye y supone una pregunta por las relaciones entre la filosofía de Zubiri, tomada en bloque, y la historia del pensamiento teológico"63. De ahí que haya sido posible enunciar como tesis "que la teología es una realidad presente en el pensamiento filosófico de Xavier Zubiri, y que [...] en sus presupuestos filosóficos encontramos las bases suficientes para llevar a cabo una reflexión teológica' ${ }^{74}$.

Ciertamente, una exposición completa y exhaustiva, por nuestra parte, de la revelación de la Trinidad en Zubiri debiera incluir en modo sistemático lo plasmado por él en su trilogía sobre la inteligencia humana. Pero esa tarea más bien

63. Ibid., p. 5.

64. J. L. Cabria Ortega, Relación Teología-Filosofia en el pensamiento de Xavier Zubiri, p. 536. 
se plantea aquí como una mera perspectiva de futuro que queda abierta, y como un verdadero reto para aquellos que exploran en Zubiri el modo cómo, desde su filosofía, el autor enfrenta algunos temas teológicos particulares en forma original y novedosa.

A mi modo de ver, pueden encontrarse en el filósofo vasco nuevas formas de decir, expresar y formular, con seriedad y altura intelectual, algunos de los más acuciantes problemas teológicos que se debaten en la actualidad y que requieren de una real y verdadera fundamentación ${ }^{65}$. En este sentido, considero esta tarea como perspectiva abierta, todavía por explorar en el filosófico vasco.

\section{Siglas usadas para la obra de Zubiri}

CLF Cinco lecciones de Filosofia, Madrid, 19997re

EPD "En torno al problema de Dios", en NDH, 417-454.

HD Hombre y Dios, Madrid, $1998^{6}$.

IL Inteligencia y logos, Madrid, 1982.

IRA Inteligencia y razón, Madrid, 1983.

IRE Inteligencia sentiente. Inteligencia y realidad, Madrid, 1991.

NHD Naturaleza, historia, Dios, Madrid, $1999^{11}$.

PFHR El problema filosófico de la historia de las religiones, Madrid, 19942re.

PTHC El problema teologal del hombre: Cristianismo, Madrid, 1997.

SH Sobre el hombre, Madrid, 1998 ${ }^{1 \mathrm{re}}$.

65. De hecho, es el modo de proceder que utiliza Zubiri con algunos temas teológicos. En concreto, destaco aquí su trabajo de madurez "Reflexiones teológicas sobre la eucaristía", en donde expresamente afirma que no pretende "decir cosas nuevas sobre la eucaristía, sino que intento conceptuar a mi modo las ya sabidas" (PTHC 397). 